\title{
Updated and New Perspectives on Diagnosis, Prognosis, and Therapy of Malignant Pheochromocytoma/Paraganglioma
}

\author{
Gabriele Parenti, ${ }^{1}$ Benedetta Zampetti, ${ }^{2}$ Elena Rapizzi, ${ }^{2,3}$ \\ Tonino Ercolino, ${ }^{1}$ Valentino Giachè, ${ }^{2}$ and Massimo Mannelli ${ }^{2,3}$ \\ ${ }^{1}$ Endocrinology Unit, Azienda Ospedaliero-Universitaria Careggi, Largo Brambilla 3, 50134 Florence, Italy \\ ${ }^{2}$ Department of Clinical Pathophysiology, University of Florence, Viale Pieraccini 6, 50139 Florence, Italy \\ ${ }^{3}$ Istituto Toscano Tumori, Via Taddeo Alderotti 26N, 50139 Florence, Italy
}

Correspondence should be addressed to Massimo Mannelli, m.mannelli@dfc.unifi.it

Received 30 April 2012; Accepted 5 June 2012

Academic Editor: Marialuisa Appetecchia

Copyright (c) 2012 Gabriele Parenti et al. This is an open access article distributed under the Creative Commons Attribution License, which permits unrestricted use, distribution, and reproduction in any medium, provided the original work is properly cited.

\begin{abstract}
Malignant pheochromocytomas/paragangliomas are rare tumors with a poor prognosis. Malignancy is diagnosed by the development of metastases as evidenced by recurrences in sites normally devoid of chromaffin tissue. Histopathological, biochemical, molecular and genetic markers offer only information on potential risk of metastatic spread. Large size, extraadrenal location, dopamine secretion, SDHB mutations, a PASS score higher than 6, a high Ki-67 index are indexes for potential malignancy. Metastases can be present at first diagnosis or occur years after primary surgery. Measurement of plasma and/or urinary metanephrine, normetanephrine and metoxytyramine are recommended for biochemical diagnosis. Anatomical and functional imaging using different radionuclides are necessary for localization of tumor and metastases. Metastatic pheochromocytomas/paragangliomas is incurable. When possible, surgical debulking of primary tumor is recommended as well as surgical or radiosurgical removal of metastases. I-131-MIBG radiotherapy is the treatment of choice although results are limited. Chemotherapy is reserved to more advanced disease stages. Recent genetic studies have highlighted the main pathways involved in pheochromocytomas/paragangliomas pathogenesis thus suggesting the use of targeted therapy which, nevertheless, has still to be validated. Large cooperative studies on tissue specimens and clinical trials in large cohorts of patients are necessary to achieve better therapeutic tools and improve patient prognosis.
\end{abstract}

\section{Introduction}

Paragangliomas (PGLs) are rare neuroendocrine tumors that arise in sympathetic and parasympathetic paraganglia and derive from neural crest cells. Approximately $80-85 \%$ of these tumour arise from the adrenal medulla and are named pheochromocytomas (PCCs), whereas $15-20 \%$ are located in extra-adrenal chromaffin tissue and are referred to as secreting paragangliomas (sPGLs). The latter term is also used to describe tumors derived from parasympathetic tissue in the head and neck (HNPGLs).

PCCs and abdominal sPGLs are usually catecholamineproducing tumours, whereas most of the HNPGLs are nonfunctioning [1].

The majority of PGLs are sporadic, but recent data have demonstrated a high prevalence of hereditary forms (approximately 35\%) [2]. Sporadic PGLs are usually diagnosed in patients older than $40-50$ years, whereas hereditary forms are diagnosed in younger patients.

Malignancy is defined by presence of metastases, tumor spread in sites where chromaffin tissue is normally absent such as lymph nodes, liver, lungs, and bones. Malignant PGLs are extremely rare. An estimated incidence in USA in 2002 was 93 cases per 400 million persons [3].

Nearly $10 \%$ and $20 \%$ of PCCs and abdominal sPGLs, respectively, are malignant [4], whereas HNPGLs are usually benign [5].

\section{Clinical Feature}

The high variability in clinical presentation of PGLs is well known [6]. It depends on the variability in the biology of 
these tumours which can express different catecholamine biosynthetic enzymes, secrete different vasoactive peptide (i.e., neuropeptide $\mathrm{Y}$, adrenomedullin, or atrial natriuretic peptide) [7], present different symptoms related to tumour mass or present symptoms related to other organs involvement in syndromic forms.

Hypertension is the most common feature of PCCs and sPGL: it can be continuous, intermittent, and often paroxysmal in nature. Hypertensive crises are frequently associated with the classic triad of severe headache, palpitations, and diaphoresis. Other signs or symptoms such as dyspnoea, weakness, arrhythmias, visual disturbances and metabolic effect such as glucose intolerance and weight loss are reported [1]. The cardiovascular complications (sudden death, myocardial infarction, hearth failure, and cerebrovascular accidents) represent the most frequent causes of morbidity and mortality in these patients.

HNPGLs are usually clinically silent, but they can determine manifestations related to mass effect or infiltration of the adjacent structures. In such situations the presence of a palpable neck mass as well as pain, dysphagia, tinnitus, or cranial nerve palsies has been reported [8].

In addition to the abovementioned symptoms and signs, malignant PGLs may also present "systemic" symptoms (anorexia, fatigue, and weight loss) or clinical manifestations related to the metastatic disease such as pain in bones affected by metastatic spread. Malignant PGLs, being lessdifferentiated tumours with a less differentiated biosynthetic pathway, generally secrete noradrenaline and/or dopamine causing even milder cardiovascular symptoms and a subclinical picture [9]. Metastatic spread may occur at presentation or even after many years from primary surgery.

\section{Diagnosis: Biochemistry}

The recommended screening test for initial assessment of PGLs is the measurement of plasma free-metanephrines or urine-deconjugated differential metanephrines [10]. In fact in comparison to plasma or urine catecohlamines and vanilmandelic acid, metanephrines show higher sensitivity, ranging around $98-99 \%[11,12]$. This is mainly related to their longer half-life and to their continuous production by the tumour where catecholamines are converted to metanephrines by the high methyltransferase activity of the chromaffin tissue [13].

The biochemical phenotype does not permit to differentiate malignant from benign PGLs.

PGLs exhibit different biochemical properties as PCCs mainly produce adrenaline, while sPGLs secrete noradrenaline. Malignant PCCs secrete predominantly noradrenaline [14], but due to an even less-differentiated catecholamine biosynthetic pathway, they may often produce mainly or exclusively dopamine [15]. Therefore, the presence of large predominantly noradrenaline-producing PGLs and increased levels of plasma dopamine or its metabolite methoxytyramine may suggest malignancy $[11,16]$.

Plasma chromogranin A ( $\mathrm{CgA})$, a protein stored and cosecreted with catecholamines, is often increased in functioning and nonfunctioning PGLs [17]. CgA shows a sensitivity of $83-89 \%$ for identifying PGLs, but it often shows false positive results because of liver or kidney failure or proton pump inhibitor therapy [18].

Malignancy is generally associated to very high plasma levels of CgA [11].

High plasma levels of neuron-specific enolase are sometimes found in patients with malignant PGLs $[19,20]$, while overexpression of secretogranin II and prohormone convertases I and II suggests a benign lesion [21].

\section{Diagnosis: Anatomical and Functional Imaging}

Anatomical imaging such as computed tomography (CT) or magnetic resonance imaging (MRI) is useful as the first radiological approach in patients with PGLs. CT shows a sensitivity of $77-98 \%$ and a specificity of $29-92 \%$ in the localization of adrenal or extra-adrenal tumors. A slightly better accuracy (sensitivity $90-100 \%$ and specificity $50-100 \%)$ has been reported for MRI, especially for the detection of extra-adrenal disease [22].

PGLs are highly vascular tumors with a high intracellular water content and frequent intratumoral cystic lesions, which show a typical, but not diagnostic, high signal on T2weighted imaging, and strong enhancement after contrastagent administration. Nevertheless, in large tumors with haemorrhagic and/or necrotic areas (features often detected in malignant lesions), the signal intensity on T2-weighted images may be low [23].

Ultrasound imaging is of limited diagnostic yield but can be useful for the detection of HNPGLs [22, 24].

After "anatomical" imaging, a "functional" imaging is generally recommended. ${ }^{131} \mathrm{I}$ or ${ }^{123} \mathrm{I}$-metaiodobenzylguanidine (MIBG) scintigraphy has been used extensively as a firstline nuclear medicine technique in evaluation of patients with PGLs. MIBG has chemical similarities to norepinephrine and is concentrated in chromaffin tissue, via the human norepinephrine transporter (hNET), that is expressed in most of chromaffin cells and it is normally responsible for catecholamines uptake [25].

${ }^{123} \mathrm{I}-\mathrm{MIBG}$ is superior to ${ }^{131} \mathrm{I}-\mathrm{MIBG}$ in terms of physical properties, quality of images, and sensitivity. ${ }^{123} \mathrm{I}$-MIBG scanning shows a sensitivity of $83-100 \%$ and a specificity of $95-100 \%$ [22]. The possibility to perform a wholebody study, may permit a better evaluation of extra-adrenal localization of the disease as well as of multiple tumors and/or metastatic sites [25]. The sensitivity of this technique in malignant PGLs may be lower as evidenced in situation highly associated with malignancy as in $S D H B$ mutation carriers (see later) or patients with dopamine-secreting tumours which usually do not uptake MIBG [26].

In patients with negative MIBG scintigraphy, other tracers may be used. The expression of somatostatin receptors (SSTRs), especially SSTR 2, 3, and 5 on chromaffin cells, represents the rationale for the use of radiolabelled somatostatin analogues in localization of these tumors. Indium-11-DTPAoctreotide ( ${ }^{111}$ In-penteotride) is the tracer most commonly used; it is of limited value in benign PCCs, but it may be 
useful in detecting extra-adrenal disease as well as MIBGnegative metastases. In fact a sensitivity near to $90 \%$ has been reported for localizing sPGLs, HNPGLs, or malignant PCCs $[22,27]$.

Somatostatin analogues labelled with gallium-68 can be used in PET imaging; ${ }^{68}$ Ga-DOTATOC (DOTA ${ }^{0}$-D-Phe ${ }^{1}$ $\mathrm{Tyr}^{3}$-octreotide) has shown a better sensitivity than ${ }^{111} \mathrm{In}$ penteotride in the detection of neuroendocrine tumors especially in detecting small lesions or neoplasms bearing only a low density of SSTR. Moreover, it permits a better identification of metastases located in the lung or in the skeleton. In relation to PGLs, this tracer seems superior to ${ }^{18} \mathrm{~F}$-labelled fluoro-deoxy-glucose $\left({ }^{18} \mathrm{~F}-\mathrm{FDG}\right)$ in detecting malignant PCCs and sPGLs [28-30].

Radiolabelled dopamine (DA) or dihydroxypheylalanine (DOPA) which are transported in to chromaffin cells by hNET, may be used as tracers in positron emission tomography (PET) imaging. PET with $6-\left[{ }^{18} \mathrm{~F}\right]$-fluoro-DA can detect metastatic PCCs with better sensitivity than ${ }^{131}$ I-MIBG [31], whereas PET with $6-\left[{ }^{18} \mathrm{~F}\right]$-fluoroDOPA is superior in imaging sPGLs and HNPGLs [32]. However, as for MIBG, these tracers show a relative low sensitivity $(70-88 \%)$ in PGLs associated with $S D H B$ gene mutations. In such conditions PET with ${ }^{18} \mathrm{~F}$-FDG shows a higher sensitivity $(97-100 \%)$ [33]; this PET scanning is useful in identifying glucose-avid metastatic lesions, particularly if they are MIBG-negative [34].

Finally PET imaging with ${ }^{11} \mathrm{C}$-hydroxyephedrine has provided high sensitivity and specificity (92 and 100\%, resp.) in the detection of PGLs, but the small number of patients studied makes not possible to draw conclusions on its utility [35].

\section{Diagnosis: Histopathologic and Molecular Markers}

Despite the increasing availability of molecular diagnostic and prognostic markers, it remains difficult to predict, on the basis of histological findings, whether an apparently benign PGL will develop in a malignant tumor. From a prognostic point of view, only relative risk factors can be taken into account. In general PGLs larger than $5 \mathrm{~cm}$ with necrotic areas as well as extra-adrenal tumors carry a higher risk of malignancy than neoplasms that are small or located in the adrenal. Several scoring systems considering invasion, histologic growth patterns, cytologic features, or mitotic activity have been proposed to calculate the risk of malignancy [36-38]. One of the most utilized score is "Pheochromocytoma of the Adrenal gland Scales Score (PASS)," proposed by Thompson on 2002. Table 1 reports the items and their values which are necessary to calculate the PASS. A PASS score $\geq 4$ was at first considered suggestive for a biological aggressive behaviour, but a later study revealed that all malignant PCCs had a PASS $>6$ [39]. On the basis of these results a PASS score $<4$ or $>6$ suggest benign and malignant lesions respectively, whereas a value between 4 and 6 suggests an intermediate risk. In any event, as none of the available scores predicts malignant development
TABLe 1: Pheochromocytoma of the adrenal gland scoring scale (PASS) [38].

\begin{tabular}{lc}
\hline Items & Value \\
\hline Nuclear hyperchromasia & 1 \\
Profound nuclear pleomorphism & 1 \\
Capsular invasion & 1 \\
Vascular invasion & 1 \\
Extension into adipose tissue & 2 \\
Atypical mitotic figures & 2 \\
Greater than 3 of 10 mitotic figures high-power field & 2 \\
Tumor cell spindling & 2 \\
Cellular monotony & 2 \\
High cellularity & 2 \\
Central or confluent tumor necrosis & 2 \\
Large nests or diffuse growth $(>10 \%$ of tumor volume) & 2 \\
\hline Total & 20 \\
\hline
\end{tabular}

unequivocally, after the removal of an isolated primary PGL, a followup of the patient is recommended in order to reveal early disease recurrence. Between histological features, high cellularity and particularly the presence of tumor necrosis are considered potential indicators of malignancy.

Further information can derive from the evaluation of specific molecular markers. Several malignancy tissue markers such as cyclooxygenase-2, secretogranin II-derived peptide, $\mathrm{N}$-cadherin, vascular endothelial growth factor (VEGF), endothelin receptor type A (ETA), and type B (ETB) and telomerase have been identified. In particular telomerase, which is a ribonucleoprotein complex that includes the telomerase RNA component, the telomeraseassociated protein (TP1), the telomerase catalytic subunit (hTERT), and the heat shock protein 90 (HSP90) seem to be closely related to the malignant potential of PGLs. In fact an upregulation of hTERT, HSP90, and telomerase activity has been evidenced in malignant cells of PCCs [40].

The Ki-67 nuclear antigen represents another potential molecular marker which has been associated with more aggressive cancers. A Ki-67 index $>3 \%$ is considered a useful parameter predicting malignant potential [41].

Another promising marker predicting metastatic potential seems the transcription factor SNAIL. Positive immunostaining has been found significantly higher in metastatic than benign PGLs [42, 43].

Novel biomarkers are recently being identified by microRNA expression profiling studies. Micro-RNA is small single-strand ( $\sim 22 \mathrm{bp})$, nonprotein coding RNA fragments, which are able to negatively regulate protein expression by either cleavage or translational repression of mRNA [44]. Recently, Meyer-Rochow, and colleagues [45] investigated 12 malignant, 12 benign tumors, and 5 healthy adrenal medulla samples. They found that miR-483-5p was overexpressed, while miR15a and miR-16, which are involved in proliferation and apoptosis, were downregulated in malignant compared to benign tumors. MicroRNA expression is tissue specific, and it has been demonstrated to be altered in several other human tumors, For these reasons, they can be of great 
TABLE 2: Correlations between gene mutations and clinical phenotype.

\begin{tabular}{|c|c|c|c|c|c|c|}
\hline Syndrome & Gene & $\begin{array}{c}\text { PCCs } \\
(\%)\end{array}$ & $\begin{array}{c}\text { Sympathetic } \\
\text { PGL }\end{array}$ & $\begin{array}{c}\text { Parasympathetic } \\
\text { PGL }\end{array}$ & $\begin{array}{c}\text { Bilateral/multifocal } \\
\text { neoplasia }\end{array}$ & $\begin{array}{c}\text { Malignancy } \\
(\%)\end{array}$ \\
\hline MEN 2A & RET & $\sim 50$ & Very rare & Extremely rare & + & $<3$ \\
\hline MEN 2B & RET & $\sim 50$ & Very rare & Extremely rare & + & $<3$ \\
\hline VHL & $V H L$ & $10-20$ & + & Rare & + & 5 \\
\hline NF1 & NF1 & 5 & - & - & - & 11 \\
\hline PGL1 & SDHD & + & + & + & + & $\sim 5$ \\
\hline PGL2 & SDHAF2 & - & - & + & + & Not known \\
\hline PGL3 & SDHC & - & Rare & + & - & Not known \\
\hline PGL4 & $S D H B$ & Rare & + & Rare & + & $\sim 40$ \\
\hline PGL5 & SDHA & - & + & - & Not known & Not known \\
\hline TMEM127 mutation carriers & TMEM127 & 100 & - & - & + & $\sim 5$ \\
\hline MAX mutation carriers & MAX & 100 & + & Extremely rare & + & $\sim 10$ \\
\hline
\end{tabular}

PCCs: pheochromocytomas; PGL: paragangliomas; +: present; -: absent.

relevance for the establishment of malignancy, but further investigations in larger cohorts of patients are necessary to confirm these encouraging results.

\section{Diagnosis: Genetic Aspects}

Until 2000, only $10 \%$ of PGLs were considered of genetic origin and linked to hereditary syndromes: von Hippel Lindau disease (VHL), multiple endocrine neoplasia type 2 (MEN2) and neurofibromatosis type 1 (NF1), due respectively to a germ line mutation in tumor-suppressor gene $\operatorname{VHL}[46,47]$, protooncogene RET [48-52] and tumor-suppressor gene NF1 [53].

In the last years it has been demonstrated that about $30 \%$ of the apparently sporadic PGLs are due to a germ-line mutation in one of the susceptibility genes [54]. This group of genes includes those encoding the four subunits $(A, B, C$, and $\mathrm{D}$ ) of the succinate dehydrogenase ( $\mathrm{SDH})$ [55-58], the recently identified gene SDHAF2, which is responsible for the flavination of the SDHA subunit [59], and the very recently discovered TMEM127 [60] and MAX [61], both mainly related to bilateral PCCs. Germ line mutations in SDHA, $S D H B, S D H C, S D H D$, and SDHAF2 genes are responsible for the occurrence of syndromes named PGL5, PGL4, PGL3, PGL1, and PGL2, respectively; to note, SDHB-mutations are generally associated with higher morbidity and mortality than mutations in the other SDHx genes [62]. A recent metaanalisis of some studies involving SDHB mutated patients has highlighted that $31 \%$ of their tumors were malignant [3].

Overall, to date, 10 susceptibility PGLs genes have been identified, so that the initial $10 \%$ of cases classified as genetically determined has increased to $30 \%$. Nevertheless, the number of the susceptibility genes is likely to increase. In fact, many young PGL patients, where the mutation frequency is higher, are still classified as sporadic, and some PGLs patients with a positive family history do not show any mutation in the so far known susceptibility genes.

Extensive genetic screening in PGLs has highlighted the correlation between genotype and phenotype thus facilitating a genetic testing algorithm based on clinical features as a guide for a more quick and cost-effective genetic screening (Table 2) [63].

Genetic analysis has also permitted to predict the malignancy risk which is higher for SDHB mutation carriers.

Furthermore, by studying tumor transcription profile, sporadic as well as hereditary PGLs have been divided in two main clusters linked to two different signalling pathways [64]: the first cluster contains all VHL- and SDHx-mutated tumors and is associated with angiogenesis, hipoxia, and reduced oxidative response [65], while the second cluster contains all RET - and NF1-mutated tumors and is associated with abnormal activation of kinase-signaling pathways, such as RAS/RAF/MAPK and PI3K/AKT/mTOR [66-69]; also TMEM127 [60] and MAX [61] mutated tumors have been associated to the activation of mTOR-signaling pathway. These data have increased overall knowledge on molecular defects in PGLs and could be used for development of new effective molecular-targeted therapies.

\section{Therapy: Surgery}

The main goal of surgical treatment is represented by the removal of primary tumor and, when possible, the resection of local and distant metastases. The overall 5-year survival rate of patients with malignant PGLs varies between $34 \%$ and $60 \%$. The survival rate may depend upon sites of metastatic lesions. In fact, patients with liver or lung metastases tend to have a worse prognosis ( $<5$ years) than patients with isolated bone lesions [2].

The preoperative management with alpha blockade and fluid administration, essential in order to avoid surgical (i.e., hypertensive crisis arrhythmias) and/or postsurgical complications (i.e., hypotension), has to be performed in all patients [1].

Laparoscopic removal of intra-adrenal and extra-adrenal PGLs is the preferred surgical technique, but, in case of large tumors with a high risk of malignancy, a transabdominal approach should be considered. In such circumstances total adrenalectomy with resection of locoregional lymph nodes or complete excision of PGLs together with the removal of 
distant metastases is recommended [70]. In case of malignant disease surgery alone is seldom curative, but surgical debulking of the tumors is regarded as a mainstay of palliative therapy. In fact, it permits to reduce local or systemic symptoms related to catecholamine secretion, it improves response to other therapeutic approaches and it may prevent further diffusion of the tumors. Pre-operative injection of ${ }^{123} \mathrm{I}$-MIBG and intraoperative application of a $\gamma$-probe may permit the localization of lesions that are not evidenced by other imaging techniques [71].

In the presence of liver metastases arterial embolisation or chemoembolisation may provide transient response, but in such circumstances radiofrequency ablation has become the preferred choice [72]. In the next future, the rapidly evolving stereotaxic radiotherapic techniques will probably represent valid alternative tools for metastasis removal.

\section{Therapy: Radiometabolic Treatment and External Radiotherapy}

Radionuclide treatment may be considered in patients with metastatic disease and no resectable lesions. It can be performed using beta-emitting isotopes coupled with MIBG or somatostatine analogue.

${ }^{131}$ I-MIBG was used in the treatment of malignant PCC for the first time in 1984 [73]. Patients are selected by the evidence of significant radioisotope uptake on diagnostic scintigraphy with ${ }^{123}$ I-MIBG or ${ }^{131}$ I-MIBG ( $>1 \%$ uptake of the injected dose). Single or fractionated doses as well as variable dosage $(200-1400 \mathrm{mCi})$ have been proposed [74, 75]. About $60 \%$ of metastatic sites are ${ }^{131}$ I-MIBG avid [76]. In general better responses are seen in patients with limited disease and in patients with soft-tissue metastases than in patients with bone metastases [77]. This treatment is well tolerated, and the main side effects are represented by transient leucopenia and thrombocytopenia, whereas severe bone marrow toxicity (associated with high-dose regimen) is rarely seen.

However treatment with ${ }^{131}$ I-MIBG is not curative in most patients; therefore, other forms of therapy need to be considered.

The presence of SSTR in PGLs has allowed treatment with radiolabelled somatostatin analogues. The most commonly used are Yttrium-90-DOTATOC $\left({ }^{90} \mathrm{Y}\right.$-DOTA-TOC) and Lutetium-177-DOTA ${ }^{0}-\mathrm{Tyr}^{3}$-octreotate ( ${ }^{177} \mathrm{Lu}$-DOTATATE) $[75,78,79]$. As for ${ }^{131}$ I-MIBG, patients are selected by the demonstration of high tumor uptake at scintigraphy. The latter is usually performed with ${ }^{111}$ In-pentetreotide, but it seems that PET using ${ }^{68} \mathrm{Ga}$-DOTA-TOC provides higher accuracy in selecting patients [34]. This kind of therapy has a low toxicity, mainly leucopenia and thrombocytopenia, and it can be effective in order to reduce hormone secretion and determine tumor shrinkage. Therefore, even if its efficacy seems lower in PGLs than in gastroenteropancreatic neuroendocrine tumors, it represents an alternative option for the treatment of surgically incurable PGLs [80]. In the future, the development of new somatostatine analogues with higher affinity for the different SSTR subtypes will provide a further possibility in the treatment of these neoplasms.
Finally a combined treatment with radiolabelled MIBG and radiolabelled somatostatin analogues might have a synergistic effect, and therefore it might be considered. Moreover, the combination treatment could permit the use of lower doses of both radionuclides, limiting side effects, particularly bone marrow toxicity.

External radiotherapy may be considered for treatment of inoperable PGLs and especially for palliation of painful bone metastases. During this procedure the patients need to be monitored because the radio-induced inflammation of the lesion can induce massive catecholamine secretion, thus inducing hypertensive crises [81].

\section{Therapy: Antineoplastic Agents}

The aim of chemotherapy is tumor size reduction and control of symptoms due to catecholamine secretion; it is usually reserved to patients with local advanced and/or metastatic disease, with unresectable lesions, resistant to treatment with radionuclide therapy [82]. Up to now, the most used and effective chemotherapy regimen is a combination of cyclophosphamide, vincristine, and daecarbazine (CVD), chosen for its use in treating another neuroendocrine tumor, neuroblastoma. It has been used for the first time in 1980s in a trial including 14 malignant PCCs cases [83], updated recently by $\mathrm{NIH}$ [84] in a 22-year followup, with demonstration of a tumor regression and symptom relief in up to $50 \%$ of patients treated and no significant change of survival. Once CVD is stopped, PCCs often recur, becoming unresponsive to the same treatment. For these reasons, CVD may have a role as a neoadjuvant therapy in few cases, to make tumors surgically resectable and to control symptoms. CVD plus anthracyclines has been tested in one case with quite a good result [85]. Other chemotherapic regimens have been tested in other trials, but currently none has demonstrated effectiveness in malignant PCCs treatment [86].

\section{Therapy: Targeted Approach}

Up to now, treatment options for malignant PGLs are limited to chemotherapy and radionuclide therapy. These often provide symptomatic and biochemical control but are less effective in causing survival increase. Understanding specific molecular pathways alteration responsible for malignant PGLs development might hopefully in the future lead to multiple molecular-targeted therapy for a successful treatment. Effectiveness of these therapies is due to a cytostatic effect, as they interfere with specific molecular targets found along the oncogenic signaling pathways responsible for carcinogenesis and tumor growth. As stated above, both benign and malignant PGLs gene mutations are part of two distinct molecular pathways leading to tumorigenesis: cluster 1 includes mutations of $V H L, S D H B$, and $S D H D$ and is associated to pseudohypoxia and aberrant VEGF signaling, leading to abnormal hypoxia inducible factor (HIF) activation and overexpression of angiogenic factors, while cluster 2 includes mutations of RET, NF1, TMEM127, and 
MAX and is associated with abnormal activation of kinasesignaling pathways such as PI3kinase/AKT, RAS/RAF/ERK, and mTOR1/p70s6K, leading to abnormal cell growth and lack of apoptosis capacity. In addition, malignant PCCs seem to overexpress HSP90, a molecular chaperone that assists in folding proteins and stabilizes various oncoproteins that play a role in malignant phenotype $[87,88]$.

Thus, HIFla inihbitors are molecular targeted drugs interfering with HIF hypoxia-driven transcription pathway, decreasing HIF activity directly, PX-478 (S-2-amino-3-[4' $\mathrm{N}, \mathrm{N}$,-bis (2-chloroethyl)amino]-phenyl propionic acid $\mathrm{N}$ oxided ihydrochloride), and indirectly, PX-12 (1-methylpropyl 2-imidazolyl disulfide). These agents have shown marked antitumoral activity in human tumor xenografts in mice and seem to be promising also for malignant PGLs, but conclusive data are missing [89-91].

The mTOR inhibitor everolimus (RAD001) in combination with octreotide has been evaluated for low- and intermediate-grade neuroendocrine tumors [92], with good results. The efficacy of everolimus has been evaluated also in malignant PGLs, but all patients experienced disease progression $[4,93]$. Maybe the low efficacy is due to a compensatory PI3K/AKT and ERK activation in response to mTOR inhibition, so a specific novel dual PI3k/mTOR inhibitor (NVP-BEZ235) might offer a novel therapeutic approach [94]. Further studies on the PI3K/AKT/mTOR pathway have to be conducted to find a more specific molecular target in its signalling.

Due to overexpression of HSP90 in malignant PCCs $[40,95]$, inhibition of its pathway could represent a future therapeutic challenge for the treatment of malignant PCCs, but at present current specific drug trials are missing.

Several studies have demonstrated overexpression in malignant PCCs of angiogenic molecules, such as VEGF, its receptor, angiopoietin-2, and the endothelin receptors ETA and ETB [96-100], leading a strong evidence that targeting this pathway with antiangiogenic therapies could represent a new promising treatment option. Accordingly, sunitinib, a receptor tyrosine kinase inhibitor acting on several targets (VEGF, PDGF, and c-KIT), with strong antiangiogenic and antitumor activity, has been used in the treatment of malignant PCCs, with promising results [101-104].

Imatinib, another tyrosine kinase inhibitor already used for hematologic and gastrointestinal stromal tumors, has not been found effective for malignant PCCs treatment [105].

Thalidomide, by targeting VEGF and basic fibroblast growth factor, is an antiangiogenic agent evaluated for treatment of metastatic renal cell cancer, multiple myeloma and nonsmall cell lung cancer $[106,107]$. It has been used in combination with Temozolomide in neuroendocrine tumors [108] obtaining an objective biochemical response rate in about $40 \%$ and a radiologic response rate in 33\% of malignant PCCs, but lymphopenia occurred in about $70 \%$ of treated patients.

Activators of prolyl hydroxylase (PHD) (such as ERBB2 inhibitors) are now on evaluation as promising antineoplastic therapies. These molecules decrease the expression levels of some angiogenic factors, such as VEGF, acting on
HIF pathway, by activating the PHD, thus increasing HIF hydroxylation, and promoting its degradation [109, 110].

Treatment of malignant PGLs is up to now basically palliative. Molecular targeted therapies are promising strategies, but, due to the complexity of these tumors pathogenesis, further studies on tumor biology, discovery of novel targeted drugs, and new trials are needed to achieve more effective treatments.

\section{Conclusions}

Malignant PGLs, as defined by the presence of metastases, are very rare and aggressive tumors. Their study is made difficult by their rarity, and the consequent limited number of patients included in the series, by their biological variability, by their variable genetic background, and by the lack of specific and sensitive histopathological or biological markers proving malignancy. Therefore, as benign tumors are diagnosed by the lack of metastases, and as metastatic spread can occur also several years after surgical removal of primary tumor, studies comparing benign and malignant PGLs need a long clinical followup of patients.

Large collaborative international studies, as those presently conducted on behalf of the European Network for the Study of Adrenal Tumors (ENS@T), are needed to improve our knowledge on the pathogenesis of these malignant tumors and to achieve a satisfactory medical treatment for affected patients.

\section{Acknowledgments}

This work has been partly supported by Fondazione Cassa di Risparmio di Pistoia e Pescia Prot. 2010.0278). Gabriele Parenti, Benedetta Zampetti, Elena Rapizzi, Tonino Ercolino, and Massimo Mannelli are members of the European Network for the Study of Adrenal Tumors (ENS@T).

\section{References}

[1] J. W. M. Lenders, G. Eisenhofer, M. Mannelli, and K. Pacak, "Phaeochromocytoma," Lancet, vol. 366, no. 9486, pp. 665675, 2005.

[2] K. Pacak, G. Eisenhofer, H. Ahlman et al., "Pheochromocytoma: recommendations for clinical practice from the First International Symposium," Nature Clinical Practice Endocrinology and Metabolism, vol. 3, no. 2, pp. 92-102, 2007.

[3] J. Welander, P. Söderkvist, and O. Gimm, "Genetics and clinical characteristics of hereditary pheochromocytomas and paragangliomas," Endocrine-Related Cancer, vol. 18, no. 6, pp. R253-R276, 2011.

[4] A. Chrisoulidou, G. Kaltsas, I. Ilias, and A. B. Grossman, "The diagnosis and management of malignant phaeochromocytoma and paraganglioma," Endocrine-Related Cancer, vol. 14, no. 3, pp. 569-585, 2007.

[5] J. H. Lee, F. Barich, L. H. Karnell et al., "National cancer data base report on malignant paragangliomas of the head and neck," Cancer, vol. 94, no. 3, pp. 730-737, 2002.

[6] M. Mannelli, L. Ianni, A. Cilotti, and A. Conti, "Pheochromocytoma in Italy: a multicentric retrospective study," 
European Journal of Endocrinology, vol. 141, no. 6, pp. 619624, 1999.

[7] E. L. Bravo, "Evolving concepts in the pathophysiology, diagnosis, and treatment of pheochromocytoma," Endocrine Reviews, vol. 15, no. 3, pp. 356-368, 1994.

[8] D. Erickson, Y. C. Kudva, M. J. Ebersold et al., "Benign paragangliomas: clinical presentation and treatment outcomes in 236 patients," Journal of Clinical Endocrinology and Metabolism, vol. 86, no. 11, pp. 5210-5216, 2001.

[9] M. Mannelli, J. V. M. Lenders, K. Pacak et al., "Subclinical pheochromocytoma," Best Practice \& Research Clinical Endocrinology \& Metabolism. In press.

[10] J. W. M. Lenders, K. Pacak, M. M. Walther et al., "Biochemical diagnosis of pheochromocytoma: which test is best?" Journal of the American Medical Association, vol. 287, no. 11, pp. 1427-1434, 2002.

[11] A. Grossman, K. Pacak, A. Sawka et al., "Biochemical diagnosis and localization of pheochromocytoma: can we reach a consensus?" Annals of the New York Academy of Sciences, vol. 1073, pp. 332-347, 2006.

[12] F. D. Davidson, "Phaeochromocytoma with normal urinary catecholamines: the potential value of urinary free metadrenalines," Annals of Clinical Biochemistry, vol. 39, no. 6, pp. 557-566, 2002.

[13] G. Eisenhofer, H. Keiser, P. Friberg et al., "Plasma metanephrines are markers of pheochromocytoma produced by catechol-O-methyltransferase within tumors," Journal of Clinical Endocrinology and Metabolism, vol. 83, no. 6, pp. 2175-2185, 1998.

[14] F. Rao, H. R. Keiser, and D. T. O’Connor, "Malignant pheochromocytoma: chromaffin granule transmitters and response to treatment," Hypertension, vol. 36, no. 6, pp. 10451052, 2000.

[15] F. M. Brouwers, G. Eisenhofer, J. J. Tao et al., "High frequency of SDHB germline mutations in patients with malignant catecholamine-producing paragangliomas: implications for genetic testing," Journal of Clinical Endocrinology and Metabolism, vol. 91, no. 11, pp. 4505-4509, 2006.

[16] E. van der Harst, W. W. de Herder, R. R. de Krijger et al., "The value of plasma markers for the clinical behaviour of phaeochromocytomas," European Journal of Endocrinology, vol. 147, no. 1, pp. 85-94, 2002.

[17] L. Guignat, J. M. Bidart, M. Nocera, E. Comoy, M. Schlumberger, and E. Baudin, "Chromogranin A and the $\alpha$-subunit of glycoprotein hormones in medullary thyroid carcinoma and phaeochromocytoma," British Journal of Cancer, vol. 84, no. 6, pp. 808-812, 2001.

[18] A. Algeciras-Schimnich, C. M. Preissner, W. F. Young, R. J. Singh, and S. K. G. Grebe, "Plasma chromogranin A or urine fractionated metanephrines follow-up testing improves the diagnostic accuracy of plasma fractionated metanephrines for pheochromocytoma," Journal of Clinical Endocrinology and Metabolism, vol. 93, no. 1, pp. 91-95, 2008.

[19] A. M. Moreno, L. Castilla-Guerra, M. C. Martínez-Torres, F. Torres-Olivera, E. Fernández, and H. Galera-Davidson, "Expression of neuropeptides and other neuroendocrine markers in human phaeochromocytomas," Neuropeptides, vol. 33, no. 2, pp. 159-163, 1999.

[20] S. Oishi and T. Sato, "Elevated serum neuron-specific enolase in patients with malignant pheochromocytoma," Cancer, vol. 61, no. 6, pp. 1167-1170, 1988.

[21] J. Guillemot, L. Barbier, E. Thouennon et al., "Expression and processing of the neuroendocrine protein secretogranin II in benign and malignant pheochromocytomas," Annals of the New York Academy of Sciences, vol. 1073, pp. 527-532, 2006.

[22] I. Ilias and K. Pacak, "Current approaches and recommended algorithm for the diagnostic localization of pheochromocytoma," Journal of Clinical Endocrinology and Metabolism, vol. 89, no. 2, pp. 479-491, 2004.

[23] M. Mannelli, S. Colagrande, A. Valeri, and G. Parenti, "Incidental and metastatic adrenal masses," Seminars in Oncology, vol. 37, no. 6, pp. 649-661, 2010.

[24] M. A. Blake, M. K. Kalra, M. M. Maher et al., "Pheochromocytoma: an imaging chameleon,” Radiographics, vol. 24, pp. S87-S99, 2004.

[25] B. L. Shulkin, I. Ilias, J. C. Sisson, and K. Pacak, "Current trends in functional imaging of pheochromocytomas and paragangliomas," Annals of the New York Academy of Sciences, vol. 1073, pp. 374-382, 2006.

[26] L. A. Dubois and D. K. Gray, "Dopamine-secreting pheochromocytomas: in search of a syndrome," World Journal of Surgery, vol. 29, no. 7, pp. 909-913, 2005.

[27] F. F. Telischi, R. Bustillo, M. L. H. Whiteman et al., "Octreotide scintigraphy for the detection of paragangliomas," Otolaryngology, Head and Neck Surgery, vol. 122, no. 3, pp. 358-362, 2000.

[28] I. Buchmann, M. Henze, S. Engelbrecht et al., "Comparison of ${ }^{68} \mathrm{Ga}$-DOTATOC PET and ${ }^{111}$ In-DTPAOC (Octreoscan) SPECT in patients with neuroendocrine tumours," European Journal of Nuclear Medicine and Molecular Imaging, vol. 34, no. 10, pp. 1617-1626, 2007.

[29] M. Hofmann, H. Maecke, A. R. Börner et al., "Biokinetics and imaging with the somatostatin receptor PET radioligand ${ }^{68} \mathrm{Ga}$-DOTATOC: preliminary data," European Journal of Nuclear Medicine, vol. 28, no. 12, pp. 1751-1757, 2001.

[30] J. Kowalski, M. Henze, J. Schuhmacher, H. R. Mäcke, M. Hofmann, and U. Haberkorn, "Evaluation of positron emission tomography imaging using $\left[{ }^{68} \mathrm{Ga}\right]$-DOTA-D Phe1-Tyr3octreotidein comparison to $\left[{ }^{111} \mathrm{In}\right]$-DTPAOC SPECT. First results in patients with neuroendocrine tumors," Molecular Imaging and Biology, vol. 5, no. 1, pp. 42-48, 2003.

[31] I. Ilias, J. Yu, J. A. Carrasquillo et al., "Superiority of 6$\left[{ }^{18} \mathrm{~F}\right]$-fluorodopamine positron emission tomography versus $\left[{ }^{131} \mathrm{I}\right]$-metaiodobenzylguanidine scintigraphy in the localization of metastatic pheochromocytoma," Journal of Clinical Endocrinology and Metabolism, vol. 88, no. 9, pp. 4083-4087, 2003.

[32] S. Hoegerle, E. Nitzsche, C. Altehoefer et al., "Pheochromocytomas: detection with ${ }^{18} \mathrm{~F}$-DOPA whole-body PET-initial results," Radiology, vol. 222, no. 2, pp. 507-512, 2002.

[33] H. J. L. M. Timmers, A. Kozupa, C. C. Chen et al., "Superiority of fluorodeoxyglucose positron emission tomography to other functional imaging techniques in the evaluation of metastatic SDHB-associated pheochromocytoma and paraganglioma," Journal of Clinical Oncology, vol. 25, no. 16, pp. 2262-2269, 2007.

[34] M. Mamede, J. A. Carrasquillo, C. C. Chen et al., "Discordant localization of $2-\left[{ }^{18} \mathrm{~F}\right]$-fluoro-2-deoxy-D-glucose in $6-\left[{ }^{18} \mathrm{~F}\right]-$ fluorodopamine- and $\left[{ }^{123} \mathrm{I}\right]$-metaiodobenzylguanidinenegative metastatic pheochromocytoma sites," Nuclear Medicine Communications, vol. 27, no. 1, pp. 31-36, 2006.

[35] C. Trampal, H. Engler, C. Juhlin, M. Bergström, and B. Långström, "Pheochromocytomas: detection with ${ }^{11} \mathrm{C} \mathrm{Hy-}$ droxyephedrine PET," Radiology, vol. 230, no. 2, pp. 423-428, 2004. 
[36] R. I. Linnoila, H. R. Keiser, S. M. Steinberg, and E. E. Lack, "Histopathology of benign versus malignant sympathoadrenal paragangliomas: clinicopathologic study of 120 cases including unusual histologic features," Human Pathology, vol. 21, no. 11, pp. 1168-1180, 1990.

[37] N. Kimura, T. Watanabe, T. Noshiro, S. Shizawa, and Y. Miura, "Histological grading of adrenal and extra-adrenal pheochromocytomas and relationship to prognosis: a clinicopathological analysis of 116 adrenal pheochromocytomas and 30 extra-adrenal sympathetic paragangliomas including 38 malignant tumors," Endocrine Pathology, vol. 16, no. 1, pp. 23-32, 2005.

[38] L. D. R. Thompson, "Pheochromocytoma of the adrenal gland scaled score (PASS) to separate benign from malignant neoplasms: a clinicopathologic and immunophenotypic study of 100 cases," American Journal of Surgical Pathology, vol. 26, no. 5, pp. 551-566, 2002.

[39] V. E. Strong, T. Kennedy, H. Al-Ahmadie et al., "Prognostic indicators of malignancy in adrenal pheochromocytomas: clinical, histopathologic, and cell cycle/apoptosis gene expression analysis," Surgery, vol. 143, no. 6, pp. 759-768, 2008.

[40] C. Boltze, J. Mundschenk, N. Unger et al., "Expression profile of the telomeric complex discriminates between benign and malignant pheochromocytoma," Journal of Clinical Endocrinology and Metabolism, vol. 88, no. 9, pp. 4280-4286, 2003.

[41] T. H. Liu, Y. J. Chen, S. F. Wu et al., "Distinction between benign and malignant pheochromocytomas," Zhonghua Bing Li Xue Za Zhi, vol. 33, no. 3, pp. 198-202, 2004.

[42] V. Häyry, K. Salmenkivi, J. Arola, P. Heikkilä, C. Haglund, and H. Sariola, "High frequency of SNAIL-expressing cells confirms and predicts metastatic potential of phaeochromocytoma," Endocrine-Related Cancer, vol. 16, no. 4, pp. 1211$1218,2009$.

[43] J. Waldmann, E. P. Slater, P. Langer et al., "Expression of the transcription factor Snail and its target gene Twist are associated with malignancy in pheochromocytomas," Annals of Surgical Oncology, vol. 16, no. 7, pp. 1997-2005, 2009.

[44] B. M. Engels and G. Hutvagner, "Principles and effects of microRNA-mediated post-transcriptional gene regulation," Oncogene, vol. 25, no. 46, pp. 6163-6169, 2006.

[45] G. Y. Meyer-Rochow, N. E. Jackson, J. V. Conaglen et al., "MicroRNA profiling of benign and malignant pheochromocytomas identifies novel diagnostic and therapeutic targets," Endocrine-Related Cancer, vol. 17, no. 3, pp. 835-846, 2010.

[46] F. Latif, K. Tory, J. Gnarra et al., "Identification of the von Hippel-Lindau disease tumor suppressor gene," Science, vol. 260, no. 5112, pp. 1317-1320, 1993.

[47] M. M. Walther, R. Reiter, H. R. Keiser et al., "Clinical and genetic characterization of pheochromocytoma in von Hippel- Lindau families: comparison with sporadic pheochromocytoma gives insight into natural history of pheochromocytoma," Journal of Urology, vol. 162, no. 3 I, pp. 659$664,1999$.

[48] H. P. H. Neumann, D. P. Berger, G. Sigmund et al., "pheochromocytomas, multiple endocrine neoplasia type 2, and von Hippel- Lindau disease," New England Journal of Medicine, vol. 329, no. 21, pp. 1531-1538, 1993.

[49] H. P. H. Neumann, D. P. Berger, G. Sigmund et al., "Erratum: pheochromocytomas, multiple endocrine neoplasia type 2, and von Hippel-Lindau disease," New England Journal of Medicine, vol. 331, no. 22, p. 1535, 1994.
[50] C. Eng, D. P. Smith, L. M. Mulligan et al., "Point mutation within the tyrosine kinase domain of the RET protooncogene in multiple endocrine neoplasia type $2 \mathrm{~B}$ and related sporadic tumours," Human Molecular Genetics, vol. 3, no. 2, pp. 237-241, 1994.

[51] C. Eng, D. P. Smith, L. M. Mulligan et al., "Erratum: point mutation within the tyrosine kinase domain of the RET proto-oncogene in multiple endocrine neoplasia type $2 \mathrm{~B}$ and related sporadic tumours," Human Molecular Genetics, vol. 3, no. 4, p. 686, 1994.

[52] C. Eng, "Seminars in medicine of the Beth Israel Hospital, Boston: the RET proto- oncogene in multiple endocrine neoplasia type 2 and Hirschsprung's disease," New England Journal of Medicine, vol. 335, no. 13, pp. 943-951, 1996.

[53] R. White and P. O'Connell, "Identification and characterization of the gene for neurofibromatosis type 1," Current Opinion in Genetics and Development, vol. 1, no. 1, pp. 1519, 1991.

[54] H. P. H. Neumann, B. Bausch, S. R. McWhinney et al., "Germ-line mutations in nonsyndromic pheochromocytoma," New England Journal of Medicine, vol. 346, no. 19, pp. 1459-1466, 2002.

[55] B. E. Baysal, R. E. Ferrell, J. E. Willett-Brozick et al., "Mutations in SDHD, a mitochondrial complex II gene, in hereditary paraganglioma," Science, vol. 287, no. 5454, pp. 848-851, 2000 .

[56] S. Niemann and U. Muller, "Mutations in SDHC cause autosomal dominant paraganglioma, type 3," Nature Genetics, vol. 26, no. 3, pp. 268-270, 2000.

[57] D. Astuti, F. Latif, A. Dallol et al., "Gene mutations in the succinate dehydrogenase subunit SDHB cause susceptibility to familial pheochromocytoma and to familial paraganglioma," American Journal of Human Genetics, vol. 69, no. 1, pp. 49$54,2001$.

[58] N. Burnichon, J. J. Brière, R. Libé et al., "SDHA is a tumor suppressor gene causing paraganglioma," Human Molecular Genetics, vol. 19, no. 15, pp. 3011-3020, 2010.

[59] H. X. Hao, O. Khalimonchuk, M. Schraders et al., "SDH5, a gene required for flavination of succinate dehydrogenase, is mutated in paraganglioma," Science, vol. 325, no. 5944, pp. 1139-1142, 2009.

[60] Y. Qin, L. Yao, E. E. King et al., "Germline mutations in TMEM127 confer susceptibility to pheochromocytoma," Nature Genetics, vol. 42, no. 3, pp. 229-233, 2010.

[61] I. Comino-Méndez, F. J. Gracia-Aznárez, F. Schiavi et al., "Exome sequencing identifies MAX mutations as a cause of hereditary pheochromocytoma," Nature Genetics, vol. 43, no. 7, pp. 663-667, 2011.

[62] A. P. Gimenez-Roqueplo, J. Favier, P. Rustin et al., "Mutations in the SDHB gene are associated with extra-adrenal and/or malignant phaeochromocytomas," Cancer Research, vol. 63, no. 17, pp. 5615-5621, 2003.

[63] M. Mannelli, M. Castellano, F. Schiavi et al., "Clinically guided genetic screening in a large cohort of Italian patients with pheochromocytomas and/or functional or nonfunctional paragangliomas," Journal of Clinical Endocrinology and Metabolism, vol. 94, no. 5, pp. 1541-1547, 2009.

[64] P. L. M. Dahia, K. N. Ross, M. E. Wright et al., "A HIf1 $\alpha$ regulatory loop links hypoxia and mitochondrial signals in pheochromocytomas," PLoS Genetics, vol. 1, no. 1, pp. 72-80, 2005.

[65] J. Favier, J. J. Brière, N. Burnichon et al., "The Warburg effect is genetically determined in inherited pheochromocytomas," PLoS One, vol. 4, no. 9, Article ID e7094, 2009. 
[66] D. Califano, C. Rizzo, A. D’Alessio et al., "Signaling through Ras is essential for ret oncogene-induced cell differentiation in PC12 cells," Journal of Biological Chemistry, vol. 275, no. 25, pp. 19297-19305, 2000.

[67] G. A. Martin, D. Viskochil, G. Bollag et al., "The GAPrelated domain of the neurofibromatosis type 1 gene product interacts with ras p21," Cell, vol. 63, no. 4, pp. 843-849, 1990.

[68] C. M. Johannessen, E. E. Reczek, M. F. James, H. Brems, E. Legius, and K. Cichowski, "The NF1 tumor suppressor critically regulates TSC2 and mTOR," Proceedings of the National Academy of Sciences of the United States of America, vol. 102, no. 24, pp. 8573-8578, 2005.

[69] C. M. Johannessen, B. W. Johnson, S. G. Williams et al., “TORC1 Is Essential for NF1-Associated Malignancies," Current Biology, vol. 18, no. 1, pp. 56-62, 2008.

[70] M. Brauckhoff, O. Gimm, and H. Dralle, "Preoperative and surgical therapy in sporadic and familial phaeochromocytoma. H. Lehnert Eds.: Phaeochromocytoma, Pathophysiology and Clinical Management," Frontiers of Hormone Research, vol. 31, pp. 121-144, 2004.

[71] T. Buhl, J. Mortensen, and A. Kjaer, "I-123 MIBG imaging and intraoperative localization of metastatic pheochromocytoma a case report," Clinical Nuclear Medicine, vol. 27, no. 3, pp. 183-185, 2002.

[72] S. K. Maithel and Y. Fong, "Hepatic ablation for neuroendocrine tumor metastases," Journal of Surgical Oncology, vol. 100, no. 8, pp. 635-638, 2009.

[73] J. C. Sisson, B. Shapiro, and W. H. Beierwaltes, "Radiopharmaceutical treatment of malignant pheochromocytoma," Journal of Nuclear Medicine, vol. 25, no. 2, pp. 197-206, 1984.

[74] G. A. Kaltsas, J. J. Mukherjee, R. Foley, K. E. Britton, and A. B. Grossman, "Treatment of metastatic pheochromocytoma and paraganglioma with ${ }^{131} \mathrm{I}$-meta-iodobenzylguanidine (MIBG)," Endocrinologist, vol. 13, no. 4, pp. 321-333, 2003.

[75] G. A. Kaltsas, D. Papadogias, P. Makras, and A. B. Grossman, "Treatment of advanced neuroendocrine tumours with radiolabelled somatostatin analogues," Endocrine-Related Cancer, vol. 12, no. 4, pp. 683-699, 2005.

[76] P. A. Fitzgerald, R. E. Goldsby, J. P. Huberty et al., "Malignant pheochromocytomas and paragangliomas: a phase II study of therapy with high-dose ${ }^{131} \mathrm{I}$-metaiodobenzylguanidine $\left({ }^{131} \mathrm{I}\right.$ MIBG)," Annals of the New York Academy of Sciences, vol. 1073, pp. 465-470, 2006.

[77] K. C. Loh, P. A. Fitzgerald, K. K. Matthay, P. P. B. Yeo, and D. C. Price, "The treatment of malignant pheochromocytoma with iodine-131 metaiodobenzylguanidine ( $\left.{ }^{131} \mathrm{I}-\mathrm{MIBG}\right)$ : a comprehensive review of 116 reported patients," Journal of Endocrinological Investigation, vol. 20, no. 11, pp. 648-658, 1997.

[78] D. J. Kwekkeboom, J. Mueller-Brand, G. Paganelli et al., "Overview of results of peptide receptor radionuclide therapy with 3 radiolabeled somatostatin analogs," Journal of Nuclear Medicine, vol. 46, no. 1, pp. S62-S66, 2005.

[79] D. J. Kwekkeboom, W. W. De Herder, B. L. Kam et al., "Treatment with the radiolabeled somatostatin analog $\left[{ }^{177} \mathrm{Lu}-\right.$ DOTA $^{0}, \mathrm{Tyr}^{3}$ ] octreotate: toxicity, efficacy, and survival," Journal of Clinical Oncology, vol. 26, no. 13, pp. 2124-2130, 2008.

[80] F. Forrer, I. Riedweg, H. R. Maecke, and J. MuellerBrand, "Radiolabeled DOTATOC in patients with advanced paraganglioma and pheochromocytoma," Quarterly Journal of Nuclear Medicine and Molecular Imaging, vol. 52, no. 4, pp. 334-340, 2008.

[81] S. Teno, A. Tanabe, K. Nomura, and H. Demura, "Acutely exacerbated hypertension and increased inflammatory signs due to radiation treatment for metastatic pheochromocytoma," Endocrine Journal, vol. 43, no. 5, pp. 511-516, 1996.

[82] K. F. Andersen, R. Altaf, A. Krarup-Hansen et al., "Malignant pheochromocytomas and paragangliomas - the importance of a multidisciplinary approach," Cancer Treatment Reviews, vol. 37, no. 2, pp. 111-119, 2011.

[83] S. D. Averbuch, C. S. Steakley, R. C. Young et al., "Malignant pheochromocytoma: effective treatment with a combination of cyclophosphamide, vincristine, and dacarbazine," Annals of Internal Medicine, vol. 109, no. 4, pp. 267-273, 1988.

[84] H. Huang, J. Abraham, E. Hung et al., "Treatment of malignant pheochromocytoma/paraganglioma with cyclophosphamide, vincristine, and dacarbazine: recommendation from a 22-year follow-up of 18 patients," Cancer, vol. 113, no. 8, pp. 2020-2028, 2008.

[85] M. Nakane, S. Takahashi, I. Sekine et al., "Successful treatment of malignant pheochromocytoma with combination chemotherapy containing anthracycline," Annals of Oncology, vol. 14, no. 9, pp. 1449-1451, 2003.

[86] R. H. Grogan, E. J. Mitmaker, and Q. Y. Duh, "Changing paradigms in the treatment of malignant pheochromocytoma," Cancer Control, vol. 18, no. 2, pp. 104-112, 2011.

[87] U. Banerji, "Heat shock protein 90 as a drug target: some like it hot," Clinical Cancer Research, vol. 15, no. 1, pp. 9-14, 2009.

[88] M. V. Powers and P. Workman, "Targeting of multiple signalling pathways by heat shock protein 90 molecular chaperone inhibitors," Endocrine-Related Cancer, vol. 13, no. 1, pp. S125-S135, 2006.

[89] G. L. Semenza, "Evaluation of HIF-1 inhibitors as anticancer agents," Drug Discovery Today, vol. 12, no. 19-20, pp. 853859, 2007.

[90] S. Welsh, R. Williams, L. Kirkpatrick, G. Paine-Murrieta, and G. Powis, "Antitumor activity and pharmacodynamic properties of PX-478, an inhibitor of hypoxia-inducible factor1 $\alpha$," Molecular Cancer Therapeutics, vol. 3, no. 3, pp. 233-244, 2004.

[91] S. J. Welsh, R. R. Williams, A. Birmingham, D. J. Newman, D. L. Kirkpatrick, and G. Powis, "The thioredoxin redox inhibitors 1-methylpropyl 2-imidazolyl disulfide and pleurotin inhibit hypoxia-induced factor lalpha and vascular endothelial growth factor formation," Molecular cancer therapeutics, vol. 2, no. 3, pp. 235-243, 2003.

[92] J. C. Yao, A. T. Phan, D. Z. Chang et al., "Efficacy of RAD001 (everolimus) and octreotide LAR in advanced lowto intermediate-grade neuroendocrine tumors: results of a phase II study," Journal of Clinical Oncology, vol. 26, no. 26, pp. 4311-4318, 2008.

[93] M. R. Druce, G. A. Kaltsas, M. Fraenkel, D. J. Gross, and A. B. Grossman, "Novel and evolving therapies in the treatment of malignant phaeochromocytoma: experience with the mTOR inhibitor everolimus (RAD001)," Hormone and Metabolic Research, vol. 41, no. 9, pp. 697-702, 2009.

[94] S. Nölting and A. B. Grossman, "Signaling pathways in pheochromocytomas and paragangliomas: prospects for future therapies," Endocrine Pathology, vol. 23, no. 1, pp. 2133, 2012.

[95] C. Boltze, H. Lehnert, R. Schneider-Stock, B. Peters, C. Hoang-Vu, and A. Roessner, "HSP90 is a key for telomerase activation and malignant transition in pheochromocytoma," Endocrine, vol. 22, no. 3, pp. 193-201, 2003.

[96] K. Salmenkivi, P. Heikkilä, J. Liu, C. Haglund, and J. Arola, "VEGF in 105 pheochromocytomas: enhanced expression correlates with malignant outcome," APMIS, vol. 111, no. 4, pp. 458-464, 2003. 
[97] A. Zielke, M. Middeke, S. Hoffmann et al., "VEGF-mediated angiogenesis of human pheochromocytomas is associated to malignancy and inhibited by anti-VEGF antibodies in experimental tumors," Surgery, vol. 132, no. 6, pp. 10561063, 2002.

[98] J. Favier, P. F. Plouin, P. Corvol, and J. M. Gasc, "Angiogenesis and vascular architecture in pheochromocytomas: distinctive traits in malignant tumors," American Journal of Pathology, vol. 161, no. 4, pp. 1235-1246, 2002.

[99] K. Kolomecki, H. Stepien, M. Bartos, and K. Kuzdak, "Usefulness of VEGF, MMP-2, MMP-3 and TIMP-2 serum level evaluation in patients with adrenal tumours," Endocrine Regulations, vol. 35, no. 1, pp. 9-16, 2001.

[100] K. Takekoshi, K. Isobe, T. Yashiro et al., "Expression of vascular endothelial growth factor (VEGF) and its cognate receptors in human pheochromocytomas," Life Sciences, vol. 74, no. 7, pp. 863-871, 2004.

[101] C. Jimenez, M. E. Cabanillas, L. Santarpia et al., "Use of the tyrosine kinase inhibitor sunitinib in a patient with von Hippel-lindau disease: targeting angiogenic factors in pheochromocytoma and other von Hippel-Lindau diseaserelated tumors," Journal of Clinical Endocrinology and Metabolism, vol. 94, no. 2, pp. 386-391, 2009.

[102] A. M. Joshua, S. Ezzat, S. L. Asa et al., "Rationale and evidence for sunitinib in the treatment of malignant paraganglioma/pheochromocytoma," Journal of Clinical Endocrinology and Metabolism, vol. 94, no. 1, pp. 5-9, 2009.

[103] K. S. Park, J. L. Lee, H. Ahn et al., "Sunitinib, a novel therapy for anthracycline- and cisplatin-refractory malignant pheochromocytoma," Japanese Journal of Clinical Oncology, vol. 39, no. 5, pp. 327-331, 2009.

[104] N. M. Hahn, M. Reckova, L. Cheng, L. A. Baldridge, O. W. Cummings, and C. J. Sweeney, "Patient with malignant paraganglioma responding to the multikinase inhibitor sunitinib malate," Journal of Clinical Oncology, vol. 27, no. 3, pp. 460463, 2009.

[105] D. J. Gross, G. Munter, M. Bitan et al., "The role of imatinib mesylate (Glivec) for treatment of patients with malignant endocrine tumors positive for c-kit or PDGF-R," EndocrineRelated Cancer, vol. 13, no. 2, pp. 535-540, 2006.

[106] S. Singhal, J. Mehta, R. Desikan et al., "Antitumor activity of thalidomide in refractory multiple myeloma," New England Journal of Medicine, vol. 341, no. 21, pp. 1565-1571, 1999.

[107] J. A. Sparano, R. Gray, B. Giantonio, P. O'Dwyer, and R. L. Comis, "Evaluating antiangiogenesis agents in the clinic: the Eastern Cooperative Oncology group portfolio of clinical trials," Clinical Cancer Research, vol. 10, no. 4, pp. 1206-1211, 2004.

[108] M. H. Kulke, K. Stuart, P. C. Enzinger et al., "Phase II study of temozolomide and thalidomide in patients with metastatic neuroendocrine tumors," Journal of Clinical Oncology, vol. 24, no. 3, pp. 401-406, 2006.

[109] H. J. Choi, B. J. Song, Y. D. Gong, W. J. Gwak, and Y. Soh, "Rapid degradation of hypoxia-inducible factor- $1 \alpha$ by KRH102053, a new activator of prolyl hydroxylase 2," British Journal of Pharmacology, vol. 154, no. 1, pp. 114-125, 2008.

[110] E. Temes, S. Martín-Puig, B. Acosta-Iborra et al., "Activation of HIF-prolyl hydroxylases by R59949, an inhibitor of the diacylglycerol kinase," Journal of Biological Chemistry, vol. 280, no. 25, pp. 24238-24244, 2005. 


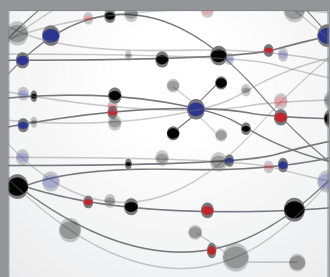

The Scientific World Journal
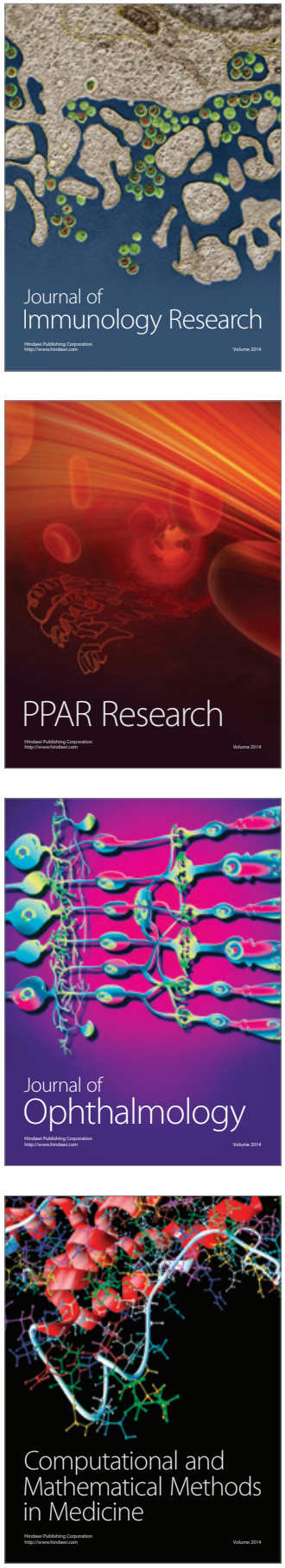

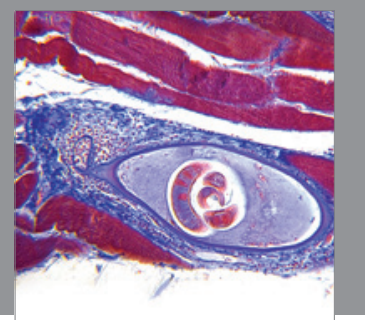

Gastroenterology

Research and Practice
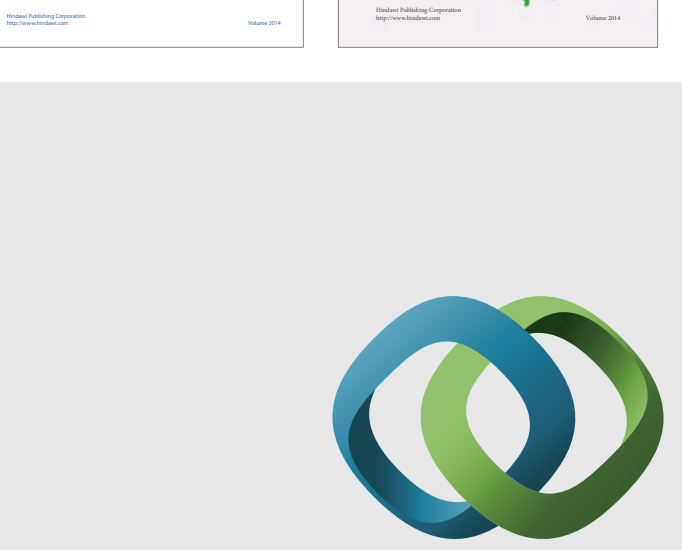

\section{Hindawi}

Submit your manuscripts at

http://www.hindawi.com
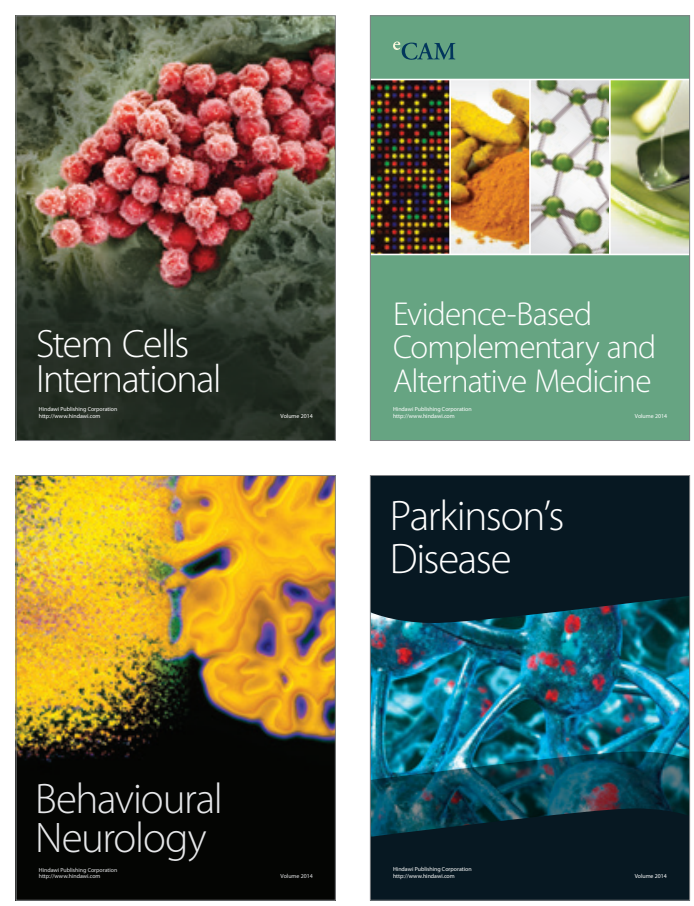

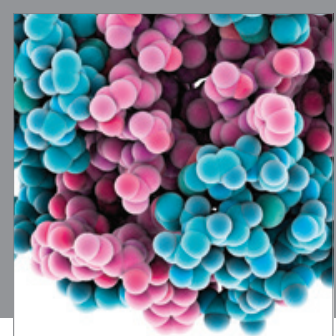

Journal of
Diabetes Research

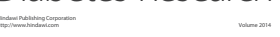

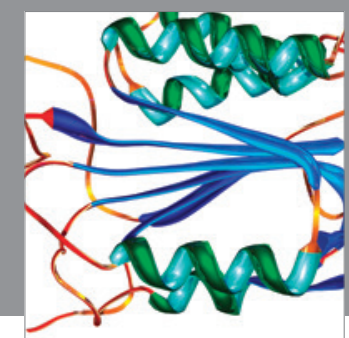

Disease Markers
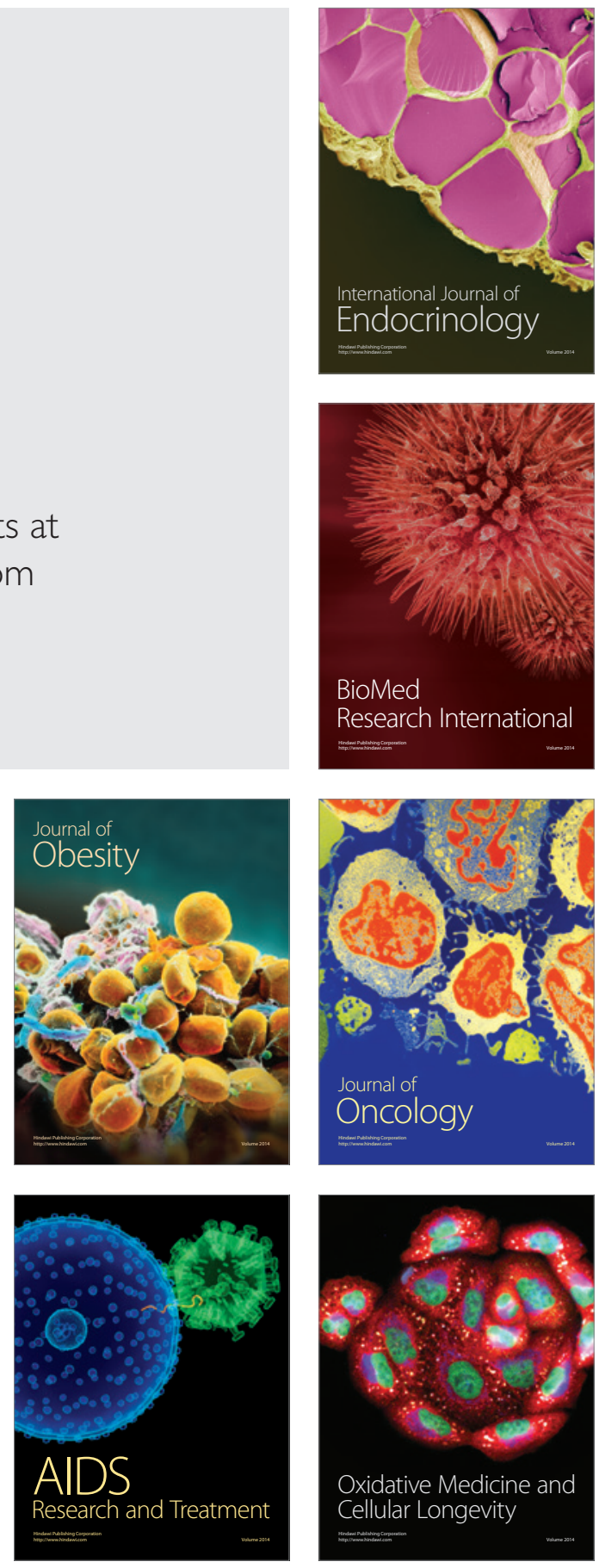